\title{
Knowledge, attitude and practices of high risk populations on louse- borne relapsing fever in Bahir Dar city, north-west Ethiopia
}

\author{
Mulat Yimer ${ }^{1}$, Bayeh Abera ${ }^{1}$, Wondemagegn Mulu ${ }^{1}$, Belay Bezabih ${ }^{2}$ \\ ${ }^{1}$ College of Medicine and Health Sciences, Bahir Dar University \\ ${ }^{2}$ Amhara National Regional State Health Bureau
}

\section{Email address:}

yimermulat@gmail.com(M. Yimer), bayeabera15@gmail.com(B. Abera),Wondem_32@yahoo.com(W. Mulu), fiametaye@yahoo.com (B. Bezabih)

\section{To cite this article:}

Mulat Yimer, Bayeh Abera, Wondemagegn Mulu, Belay Bezabih. Knowledge, Attitude and Practices of High Risk Populations on LouseBorne Relapsing Fever in Bahir Dar City, North-West Ethiopia. Science Journal of Public Health. Vol. 2, No. 1, 2014 , pp. 15-22. doi: 10.11648/j.sjph.20140201.13

\begin{abstract}
Background: Louse- borne relapsing fever (LBRF) is an acute febrile illness caused by Borrelia recurrentis (B. recurrentis). It is transmitted by body lice, Pediculus humanus corporis (P. humanus corporis). LBRF is more prevalent in high risk populations such as prisoners, street children and yekolotemaries (traditional students of the Ethiopian Orthodox Church with low levels of socio economic status and poor personal hygiene). Thus, this study was conducted to assess the knowledge, attitude and practices (KAPs) among high risk populations towards LBRF prevention in Bahir Dar city. Methods: A cross- sectional survey was conducted on KAPs of high risk populations regarding LBRF from November to December, 2012. Data was collected using a standardized pre- tested closed ended questionnaire by face to face interviews to address socio demographic characteristics, KAPs and sources of information regarding LBRF prevention. The overall KAPs of the study participants were analyzed using the sum score of each outcome based on Bloom's cut-off point (60-80\%). Having a score above the cut-off point was equated with having high levels of knowledge, positive attitude and good practice. Results: Of the 407 study participants, 383 (94.1\%) were males with the mean age of 31 years. Among the study participants, 243 (59.7\%) had no formal education. The response rate of the participants was $98.2 \%$. Overall, 222 (54.5\%) of the study participants had low knowledge, 247(60.7\%) had neutral attitude (30-39 scores out of 50 item- questions on LBRF) and 320 (78.6\%) had fair practice (20-25 scores out of 32 item-questions). Prisoners had the highest knowledge, attitude and practices followed by street children and yekolotemaries towards LBRF prevention $(p<0.001)$. Conclusion: The overall KAPs of the high risk populations towards prevention of LBRF were poor. However, prisoners had highest level followed by street children and yekolotemaries. Moreover, the sources of information on LBRF received by the high risk populations have determined their KAP levels towards LBRF prevention. This showed that information on LBRF using television, radio and through their friends is essential to bring knowledge and attitudinal change towards LBRF prevention.
\end{abstract}

Keywords: Knowledge, Attitude and Practices, Louse- Borne Relapsing Fever, Bahir Dar City, Ethiopia

\section{Introduction}

Relapsing fever (RF) is a vector borne disease caused by Borrelia species (body lice in case of louse- borne relapsing fever (LBRF) and soft ticks in case of tick- borne relapsing fever (TBRF). This acute febrile illness presents with recurrence of characteristic febrile periods lasting for days alternating with afebrile periods [1]. The main manifestation is a recurring fever which coincides with massive numbers of bacteria in the blood and severity ranges from asymptomatic to fatal [2].

It is reported that 15 million cases and greater than 5 million deaths of LBRF occurred in Africa, Eastern Europe and Russia [3]. Although it is a worldwide problem, it is most common in Africa where it is one of the most prevalent bacterial diseases. In the past, LBRF had also occurred in large outbreaks in Eritrea, Sudan and Somalia [4]. However, there is no data that depicts the designed controlling mechanism. Transmission of $B$. recurrentis back to humans is accomplished when the louse is crushed while scratching and enters through the abraded skin $[5,6]$ and also facilitated 
through lice faeces [7].

TBRF in Africa is caused primarily by Borrelia duttonii, transmitted by Orinthodoros moubata ticks in East and Central Africa, and by Borrelia crocidurae, transmitted by Orinthodoros sonrai in West Africa. African TBRF is associated with proximity to tick-infested burrows and huts $[8,9]$. In contrast, LBRF is caused by $B$. recurrentis, which is transmitted by body louse ( $P$. humanus corporis). This vector lives in clothes and multiplies when conditions like cold weather, lack of hygiene, or war are present. Its prevalence reflects the socioeconomic level of the society, as it is increasingly described in the poorest populations [10].

LBRF is now an important disease in the highlands of Ethiopia where an estimated 10,000 cases occur annually and affects mostly homeless people living in crowded and unhygienic conditions especially during rainy seasons [11]. It is within the top ten causes of hospital admissions, associated with significant morbidity and mortality [2, 8]. For instance, in southern Ethiopia (Hosanna hospital), LBRF admissions comprised $27 \%$ of total admissions [2]. Moreover, in south west Ethiopia, $6 \%$ of mortality rate was documented [12]. Moreover, according to the Ethiopian health department report, it is the seventh most common cause of hospital admission and fifth most common cause of death [13].

In 2010, it is also occurring as epidemic at Bahir Dar town and 2-3 patients on average were admitted at Felegehiwot referral hospital per day [data from the registration book]. This is may be related to internal migration of highlanders in to Bahir Dar city for employment opportunity and as a daily labourer and rent rooms in groups at the slum areas of the city.

Regards to the vector body lice; P. humanus corporis, infestation is common in different towns of Ethiopia; for example, $66.8 \%$ of school children were found to be infested in a study by Tesfayohannes [14].

Studies showed that factors affecting practices towards prevention of LBRF are: age, sex, educational status, knowledge and attitude [15]. Although, LBRF has been known for several centuries, they remain a major public health concern in populations living in poor-hygiene conditions because of war, social disruption and severe poverty. Moreover, overcrowding conditions like in military camps, prison, street children sleeping sites are the major foci for LBRF $[2,5]$. All the above conditions favor a higher prevalence of body lice, which are the main vectors for the disease especially in these high risk populations.

In spite of having the disease in these high risk populations, yet the KAPs of these populations about LBRF is not known in Ethiopia, especially in Bahir Dar city. Therefore, this study was conducted to assess the KAPs of high risk populations towards LBRF.

\section{Methods}

\subsection{Study Period and Area}

A cross- sectional survey on KAPs of high risk populations regarding LBRF at Bahir Dar city was conducted from November to December, 2012. Bahir Dar is situated on the southern shore of Lake Tana, the source of the Blue Nile (or Abay), in what was previously the Gojjam province and now the Amhara National Regional State. The city is located approximately $578 \mathrm{~km}$ north-northwest of Addis Ababa, having an elevation of 1840 meters above sea level. Based on the 2007 Census conducted by the Central Statistical Agency of Ethiopia, this city has a total population of 221,991 , an increase of $130.90 \%$ over the population recorded in the 1994 census, of whom 108,456 are men and 113,535 women[16].

The source and study populations were those perceived to be high risk groups in Bahir Dar city including prisoners, street children and yekolotemaries. Study participants were randomly selected and volunteered to participate in the survey.

In this survey, sample size was determined assuming that $50 \%$ of the high risk populations lacked knowledge, or practiced preventative measures. Moreover, marginal error of $5 \%$ and $95 \%$ confidence interval with non response rates of $10 \%$ of the sample size was included. Using single proportion formula, 415 study participants were determined to be necessary. Then, using stratified random sampling method, the sample size for each stratum was determined by proportionate allocation to total number of risk populations. Therefore, 234, 82 and 99 participants were included from prisoners, street children and yekolotemaries, respectively. However, 8 (1.92\%) prisoners give up answering the questionnaire from the total 415 respondents thus 407 participants were included.

The following conceptual framework was used as a method to explain the factors affecting practices towards prevention of LBRF.

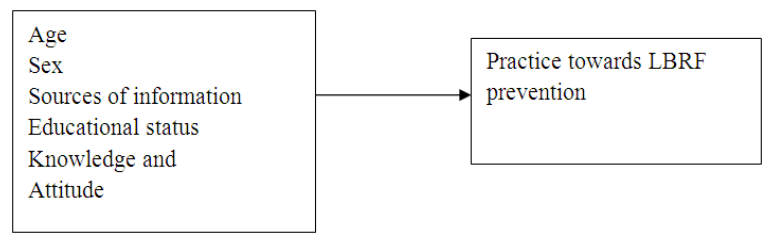

Fig. 1 Conceptual frame work of the study.

\subsection{Survey Instruments}

A standardized questionnaire was developed and the questionnaire consists of five parts to address socio demographic characteristics, KAPs and sources of information regarding LBRF prevention. Data was collected using a pre- tested closed ended questionnaire by face to face interviews. The overall KAPs of the study participants were assessed using the sum score of each outcome based on Bloom's cut-off point (60-80\%). Having a score above the cut-off point was equated with having high levels of knowledge, positive attitude and good practice (Appendix- I).

\subsection{Data Analysis}

Data was checked for completeness, coded and analysed 
using SPSS version 16. For descriptive statistics, frequency, percentage, mean and standard deviation were used. While for categorical analysis, Chi-square was used to describe the association between variables and $\mathrm{p}<0.05$ was considered significant for comparison. Moreover, the following operational definitions were used.

Knowledge: The knowledge that the respondents had regarding the prevention of LBRF.

Attitude: The feeling and beliefs of respondents with regard to the prevention of LBRF.

Practice: The actions intended to do in order to prevent infection from LBRF.

High risk populations: Are those people who are living in conditions of overcrowding and poor hygiene.

Yekolotemaries: Are students who are from rural families of Ethiopia dedicated to learn in the Ethiopian Orthodox Church to become priests. They are grouped in low socio economic status; their lively hood is based on lobbing of foods like Ethiopian local foods from houses to houses. They live in mud houses and their hygienic condition is poor because they believe that being hygienic could reduce their learning capacities.

High levels of knowledge: Study participants who had scores of 7-9 out of 9 questions about prevention of LBRF.

Moderate level: Study participants who had scores of 4-6 out of 9 questions about prevention of LBRF.

Low level: Study participants who had scores of $0-3$ out of 9 questions about prevention of LBRF.

Positive attitude: Study participants who had scores of 40-50 out of 50 questions about prevention of LBRF.
Neutral attitude: Study participants who had scores of 30-39 out of 50 questions about prevention of LBRF.

Negative attitude: Study participants who had scores of 0-29 out of 50 questions about prevention of LBRF.

Good practice: Study participants who had scores of 26-32 out of 32 questions about prevention of LBRF.

Fair practice: Study participants who had scores of 20-25 out of 32 questions about prevention of LBRF.

Poor practice: Study participants who had scores of 0- 19 out of 32 questions about prevention of LBRF.

\subsection{Ethical Consideration}

Ethical clearance was obtained from Bahir Dar University, College of Medicine and Health Sciences and Amhara National Regional State Health Bureau. The study participants were informed about the study in their language, including the purpose of the study. For those who were illiterate, the informed consent was read. Only those study participants who were agreed and signed the informed consent were included.

\section{Results}

In this survey, of the 407 study participants, the male to female ratio was 4:1 and majority of the participants were males $383(94.1 \%)$. The mean ages of the participants were 31 years with a standard deviation of 15.5 . Regards to educational levels, $243(59.7 \%)$ had no formal education (Table 1).

Table 1 Distribution of high risk populations for louse- borne relapsing fever by socio demographic characteristics in Bahir Dar city, from November to December, 2012.

\begin{tabular}{|c|c|c|c|c|}
\hline \multirow{4}{*}{ Characteristic } & \multicolumn{4}{|c|}{ High risk populations } \\
\hline & \multirow{2}{*}{$\begin{array}{l}\text { Prisoners } \\
(n=226)\end{array}$} & \multirow{2}{*}{$\begin{array}{l}\text { Street children } \\
(n=82)\end{array}$} & \multirow{2}{*}{$\begin{array}{l}\text { Yekolotemaries } \\
(n=99)\end{array}$} & \multirow{2}{*}{$\begin{array}{l}\text { Total } \\
(n=407)\end{array}$} \\
\hline & & & & \\
\hline & No $(\%)$ & No $(\%)$ & No $(\%)$ & No $(\%)$ \\
\hline & \multicolumn{4}{|c|}{ Sex } \\
\hline Male & $226 \quad(59)$ & $58 \quad(15)$ & $99 \quad(25.8)$ & $383 \quad(94.1)$ \\
\hline Female & 0 & $24 \quad(100)$ & 0 & $24 \quad(5.9)$ \\
\hline Total & $226 \quad(55.5)$ & $82 \quad(20.1)$ & $99 \quad(24.3)$ & $407(100.0)$ \\
\hline \multicolumn{5}{|l|}{ Age group in years } \\
\hline $11-20$ & $33 \quad(23.7)$ & $27 \quad(19.2)$ & $79 \quad(56.8)$ & $139 \quad(43.2)$ \\
\hline $21-30$ & $79 \quad(69.9)$ & $16 \quad(14.2)$ & $18 \quad(15.9)$ & $113 \quad(27.8)$ \\
\hline $31-40$ & $(79.4)$ & $13 \quad(20.6)$ & 0 & $63 \quad(15.6)$ \\
\hline $41-50$ & $31 \quad(81.6)$ & $5 \quad(13.2)$ & $(5.3)$ & $(9.3)$ \\
\hline$\geq 51$ & $33 \quad(61)$ & (38.9) & 0 & $(13.3)$ \\
\hline Total & $226 \quad(55.5)$ & (20.1) & $99 \quad(24.3)$ & $407(100.0)$ \\
\hline \multicolumn{5}{|l|}{ Educational status } \\
\hline No formal & $95 \quad(39.1)$ & $53 \quad(21.8)$ & (39.1) & $243 \quad(59.7)$ \\
\hline $1-8$ grades & $74 \quad(71.8)$ & $(24.3)$ & $(3.9)$ & $103 \quad(25.5)$ \\
\hline $9-12$ grades & $(95.3)$ & $(4.6)$ & 0 & $43 \quad(10.6)$ \\
\hline Diploma \& above & $(88.9)$ & (11.1) & 0 & $(4.4)$ \\
\hline Total & $226 \quad(55.5)$ & 82 (20.1) & $99 \quad(24.3)$ & $407 \quad(100)$ \\
\hline \multicolumn{5}{|l|}{ Marital status } \\
\hline Married & $118 \quad(90.7)$ & $(5.4)$ & $5 \quad(3.8)$ & $130 \quad(31.9)$ \\
\hline Single & $82 \quad(37.4)$ & $44 \quad(20.1)$ & $93 \quad(42.5)$ & $219 \quad(53.9)$ \\
\hline Divorced & $26 \quad(46.4)$ & $29 \quad(51.8)$ & $1 \quad(1.9)$ & $56 \quad(13.8)$ \\
\hline Widowed & 0 & $2 \quad(100)$ & 0 & $(0.5)$ \\
\hline Total & $226 \quad(55.5)$ & $82 \quad(20.1)$ & $99 \quad(24.3)$ & (100) \\
\hline
\end{tabular}


Among the respondents, 219 (53.8\%) had no knowledge regarding LBRF, while only $35(8.6 \%)$ had received some sorts of information from television and radio (Table 2).

Table 2 Distribution of the sources which the high risk populations received information regards to louse- borne relapsing fever, in Bahir Dar city, from November to December, 2012.

\begin{tabular}{|c|c|c|c|c|}
\hline Characteristic & $\begin{array}{l}\text { High risk populations } \\
\text { Prisoners } \\
(\mathrm{n}=226) \\
\text { No }(\%) \\
\end{array}$ & $\begin{array}{l}\text { Street children } \\
(\mathrm{n}=82) \\
\text { No }(\%)\end{array}$ & $\begin{array}{l}\text { Yekolotemaries } \\
(\mathrm{n}=99) \\
\text { No }(\%)\end{array}$ & $\begin{array}{l}\text { Total } \\
(\mathrm{n}=407) \\
\text { No }(\%) \\
\end{array}$ \\
\hline \multicolumn{5}{|c|}{ Source of information } \\
\hline TV and Radio & $35 \quad(100)$ & 0 & 0 & $35 \quad(8.6)$ \\
\hline Friends & $84 \quad(58.3)$ & $30 \quad(26.3)$ & 0 & $114 \quad(28)$ \\
\hline All of the above & $37 \quad(94.9)$ & $2 \quad(5.1)$ & 0 & $39 \quad(9.6)$ \\
\hline None of the above & $70 \quad(31.9)$ & $50 \quad(22.8)$ & $99 \quad(45.2)$ & $219(53.8)$ \\
\hline Total & $226 \quad(55.5)$ & $82 \quad(20.1)$ & $99 \quad(24.3)$ & $407(100)$ \\
\hline
\end{tabular}

TV, Television

Of the 407 high risk populations, 222 (54.5\%) of participants had low and $168(41.3 \%)$ of them had moderate while 17 (4\%) had high levels of knowledge. 90 (22.1\%) of the respondents had positive attitude, $247(60.7 \%)$ of them had neutral attitude, while $70(17.2 \%)$ had negative attitude. $34(8.6 \%)$ of the respondents had good practice, $320(78.6 \%)$ of them had fair practice, while $53(13 \%)$ had poor practice for LBRF prevention (Table 3).

The KAP levels among each study participants on LBRF showed that $70(31.5 \%)$ of prisoners, $57(25.7 \%)$ of street children and 95 (42.8\%) of yekolotemaries had low levels of knowledge $(\mathrm{P}<0.001)$. Regards to attitude, $80(88.9 \%)$ of prisoners and $10(11 \%)$ of street children had positive attitude. While all of yekolotemaries had nil $(0 \%)(\mathrm{P}<0.001)$. Concerning with practices towards prevention of LBRF, prisoners demonstrate $32(94.1 \%)$, street children $2(5.9 \%)$. However, all yekolotemaries failed to demonstrate good practices $(0 \%)(\mathrm{P}<0.001)$ (Table 3$)$.

When we compare the KAP levels of the three types of study participants, prisoners had highest level (13\%, 80\% and $32 \%)$ followed by street children $(4 \%, 10 \%$ and $2 \%)$ and yekolotemaries had nil (0\%) respectively. Street children had less KAP levels than prisoners and had more KAP levels than yekolotemaries towards LBRF prevention $(\mathrm{P}<0.001)$ (Table 3).

Table 3 Distribution and associations of knowledge, attitude and practices among high risk populations on louse- borne relapsing fever in Bahir Dar city, from November to December, 2012.

\begin{tabular}{|c|c|c|c|c|c|}
\hline \multirow{4}{*}{ Characteristic } & \multicolumn{5}{|c|}{ High risk populations } \\
\hline & \multirow{2}{*}{$\begin{array}{l}\text { Prisoners } \\
(n=226)\end{array}$} & \multirow{2}{*}{$\begin{array}{l}\text { Street children } \\
(n=82)\end{array}$} & \multirow{2}{*}{$\begin{array}{l}\text { Yekolotemaries } \\
(n=99)\end{array}$} & \multirow{2}{*}{$\begin{array}{l}\text { Total } \\
(n=407)\end{array}$} & \multirow{3}{*}{$P$ value } \\
\hline & & & & & \\
\hline & No (\%) & No (\%) & No (\%) & No $(\%)$ & \\
\hline & & \multicolumn{4}{|c|}{ Knowledge } \\
\hline High level & $13 \quad(76.5)$ & $4 \quad(23.5)$ & 0 & $17(4.0)$ & \\
\hline Moderate level & $143 \quad(85)$ & $21 \quad(12.5)$ & $(2.4)$ & $168(41.3)$ & \\
\hline Low level & $70 \quad(31.5)$ & $57 \quad(25.7)$ & $(42.5)$ & $222(54.5)$ & \\
\hline Total & $226(55.5)$ & $82 \quad(20.1)$ & $99 \quad(24.3)$ & $407(100)$ & $<0.001$ \\
\hline \multicolumn{6}{|l|}{ Attitude } \\
\hline Positive & $80 \quad(88.9)$ & $10 \quad(11)$ & 0 & $90 \quad(22.1)$ & \\
\hline Neutral & $124 \quad(50.2)$ & $56 \quad(22.7)$ & $67 \quad(27.1)$ & $247(60.7)$ & \\
\hline Negative & $22 \quad(31.4)$ & $16 \quad(22.8)$ & $32 \quad(45.7)$ & $70 \quad(17.2)$ & \\
\hline Total & $226 \quad(55.5)$ & $82 \quad(20.1)$ & $99 \quad(24.3)$ & $407(100)$ & $<0.001$ \\
\hline \multicolumn{6}{|l|}{ Practice } \\
\hline Good practice & $32 \quad(94.1)$ & $2(5.9)$ & 0 & $34(8.6)$ & \\
\hline Fair practice & $181 \quad(56.7)$ & $75(23.4)$ & $64 \quad(20)$ & $320(78.6)$ & $<0.001$ \\
\hline Poor practice & $13 \quad(24.5)$ & $5(9.4)$ & $35 \quad(66)$ & $53 \quad(13)$ & \\
\hline Total & $226 \quad(55.5)$ & $82(20.1)$ & $99 \quad(24.3)$ & $407(100)$ & \\
\hline
\end{tabular}

Association between sociodemographic characteristics with practices towards prevention of LBRF showed that males demonstrate good practices $34(8.9 \%)$. Those age groups from 21-30 had good practices 19(16.8\%). Moreover, high risk populations who were married had good practices $14(10.8 \%)$. Furthermore, those who have had diploma and above $9(50 \%)$ showed good practice towards prevention of LBRF (Table 4). 
Table 4 Association between socio demographic characteristics and levels of practices of high risk populations on louse- borne relapsing fever in Bahir Dar city, from November to December, 2012

\begin{tabular}{|c|c|c|c|c|c|c|c|c|}
\hline \multirow{2}{*}{$\begin{array}{l}\text { Characteristics } \\
\text { Sex }\end{array}$} & \multicolumn{8}{|c|}{ Levels of practice } \\
\hline & $\begin{array}{l}\text { Good practice } \\
\text { No }(\%)\end{array}$ & \multicolumn{2}{|c|}{$\begin{array}{l}\text { Fair practice } \\
\text { No }(\%)\end{array}$} & \multicolumn{2}{|c|}{$\begin{array}{l}\text { Poor practice } \\
\text { No }(\%)\end{array}$} & \multicolumn{2}{|c|}{$\begin{array}{l}\text { Total } \\
\text { No }(\%)\end{array}$} & P value \\
\hline Male & $34(8.9)$ & 296 & (77.3) & 53 & $(13.8)$ & 383 & (94.1) & \\
\hline Female & 0 & 24 & $(100)$ & 0 & & 24 & $(5.9)$ & \\
\hline Total & $34(8.4)$ & 320 & (78.6) & 53 & (13) & 407 & (100) & $<0.0031$ \\
\hline \multicolumn{9}{|l|}{ Age in years } \\
\hline $11-20$ & (2.9) & 104 & $(74.8)$ & 31 & $(22.3)$ & 139 & $(34.2)$ & \\
\hline $21-30$ & $19 \quad(16.8)$ & 85 & $(75.2)$ & 9 & $(7.9)$ & 113 & $(27.7)$ & \\
\hline $31-40$ & $3 \quad(4.7)$ & 50 & (79.4) & 10 & (15.9) & 63 & $(15.5)$ & \\
\hline $41-50$ & $6 \quad(15.8)$ & 32 & $(84.2)$ & 0 & & 38 & $(9.3)$ & $<0.001$ \\
\hline$\geq 51$ & $2 \quad(3.7)$ & 49 & (90.7) & 3 & $(5.6)$ & 54 & $(13.3)$ & \\
\hline Total & $34 \quad(8.4)$ & 320 & (78.6) & 53 & (13) & 407 & $(100)$ & \\
\hline \multicolumn{9}{|l|}{ Marital status } \\
\hline Single & $16 \quad(7.3)$ & 161 & $(73.5)$ & 42 & $(19.2)$ & 219 & $(53.8)$ & \multirow{5}{*}{$<0.009$} \\
\hline Married & $14(10.8)$ & 108 & & 8 & (6) & 130 & (31.9) & \\
\hline Widowed & 0 & \multicolumn{2}{|c|}{$2 \quad(100)$} & 0 & & 2 & $(0.5)$ & \\
\hline Divorced & $4 \quad(7.1)$ & & $(87.5)$ & 3 & (5.4) & 56 & (13.8) & \\
\hline \multirow{2}{*}{\multicolumn{9}{|c|}{ Education }} \\
\hline & & & & & & & & \\
\hline No formal & $12 \quad(4.9)$ & 193 & (79.4) & 38 & $(15.6)$ & 243 & $(59.7)$ & \multirow{5}{*}{$<0.001$} \\
\hline $1-8$ grades & $8 \quad(7.8)$ & 83 & $(80.6)$ & 12 & $(11.6)$ & 103 & $(25.3)$ & \\
\hline $9-12$ grades & $5 \quad(11.6)$ & 37 & (86) & 1 & $(2.3)$ & 43 & (10.6) & \\
\hline Diploma \& above & $(50)$ & 7 & ( 38.9$)$ & 2 & $(11.1)$ & 18 & $(4.4)$ & \\
\hline Total & $34 \quad(8.4)$ & 320 & (78.6) & 53 & (13) & 407 & (100) & \\
\hline
\end{tabular}

An attempt also made to determine the association between knowledge and attitude with practices towards prevention of LBRF. This showed that those high risk populations who had high levels of knowledge $(0 \%)$ had no good practices. While those who had positive attitude $12(13.3 \%)$ had good practice towards prevention of LBRF (Table 5).

Table 5 Association between knowledge and attitude with levels of practice of high risk populations on louse -borne relapsing fever in Bahir Dar city, from November to December, 2012.

\begin{tabular}{|c|c|c|c|c|c|}
\hline \multirow[b]{2}{*}{ Characteristic } & \multicolumn{5}{|l|}{ Levels of practice } \\
\hline & $\begin{array}{l}\text { Good practice } \\
\text { No }(\%)\end{array}$ & $\begin{array}{l}\text { Fair practice } \\
\text { No }(\%)\end{array}$ & $\begin{array}{l}\text { Poor practice } \\
\text { No }(\%)\end{array}$ & $\begin{array}{l}\text { Total } \\
\text { No (\%) }\end{array}$ & P value \\
\hline High level & 0 & $17(100)$ & 0 & $17(4.2)$ & \\
\hline Moderate level & $22(13.1)$ & $134(79.8)$ & $12(7.1)$ & $168(41.3)$ & \\
\hline Low level & $12 \quad(5.4)$ & $169(76.1)$ & 41 (18.7) & $222(54.5)$ & \\
\hline Total & $34 \quad(8.4)$ & 320 (78.6) & 53 (13) & $407(100)$ & $<0.002$ \\
\hline Attitude & & & & & \\
\hline Positive & $12(13.3)$ & $75(83.3)$ & $3(3.3)$ & $90 \quad(22.1)$ & \\
\hline Neutral & $15(6.1)$ & $198(80.2)$ & 34 (13.8) & 247 (60.7) & \\
\hline Negative & $7 \quad(10)$ & $47 \quad(67.1)$ & $16(22.9)$ & $70 \quad(17.2)$ & $<0.001$ \\
\hline Total & $34(8.4)$ & $320 \quad(78.6)$ & $53(13)$ & 407 (100) & \\
\hline
\end{tabular}

\section{Discussion}

In this survey, the overall KAPs about LBRF among high risk populations showed that majority of the respondents had low levels of knowledge, neutral attitude and fair practices. This might be explained by the shortage of information about LBRF since the majority of the respondents replied that they had no any sorts of information regards to LBRF (Table 2). Moreover, $59.7 \%$ of the high risk populations for
LBRF did not attend formal education (Table 1). Although, the study area and participants were different, a study conducted in southern part of Ethiopia reported that $81 \%$ of patients with LBRF had no knowledge on LBRF [2].

Among high risk populations, prisoners had high levels of knowledge, positive attitude and good practice behavior as compared to street children and yekolotemaries $(\mathrm{P}<0.001)$. And street children had high levels of knowledge, positive attitude and good practice behavior as compared to yekolotemaries. Moreover, yekolotemaries had low level of 
knowledge, no positive attitude and no good practice behavior as compared to prisoners and street children ( $\mathrm{P}$ $<0.001$ ) (Table3). This difference might be related to lack of information about LBRF as $100 \%$ of yekolotemaries had no information on LBRF (Table 2).

We attempted to determine the association between knowledge levels with preventive practices for LBRF. All study participants who had high levels of knowledge showed fair practices. And those who had low levels of knowledge revealed poor practices. It is clear that information on LBRF was insufficient to bring positive attitude in order to practice on prevention of LBRF. Therefore, knowledge of respondents had significant association with levels of practices towards LBRF prevention $(\mathrm{p}<0.002)$ (Table 5).

Regarding to attitude of respondents, most of them had neutral attitude. The majority of the study participants revealed fair practice behaviors (study participants who had 20-25 scores out of 32 questions about prevention of LBRF). Those participants who had positive attitude showed good practice behaviors compared to those who had neutral and negative attitudes. Therefore, attitude of participants towards LBRF had significant association with levels of practice behaviors towards LBRF prevention $(\mathrm{p}<0.001)$ (Table 5).

The overall KAP levels of the three high risk populations were compared and prisoners had highest level followed by street children and yekolotemaries. This is because $68 \%$ of prisoners had heard some sorts of information using television, radio and from their friends about prevention of LBRF. Although street children had less KAP levels than prisoners, they had more KAP levels than yekolotemaries towards LBRF prevention $(\mathrm{P}<0.001)$ (Table 3$)$. This is because, $39 \%$ of the street children had heard information using the above media where as all yekolotemaries had not heard information regards to prevention of LBRF (Table 2). Moreover, this might be also associated with difference in educational levels because, $88.9 \%$ of prisoners and $11.1 \%$ of street children had diploma and above respectively. However, yekolotemaries had nil (Table 1).

Generally, it was clear from Table 2 that as the sources of information received by the high risk populations' decreases, their KAP levels towards LBRF prevention also decreases proportionally (Table 3 ). This showed that information on items assessing on knowledge and attitude towards LBRF prevention using television, radio and from their friends is essential to bring knowledge and attitudinal change. Moreover, face to face health education should also be delivered for the high risk populations to reduce infection from LBRF.

It is acknowledged that this study was focused only on high risk populations and therefore not representative of the whole population. Therefore, further study should be carried out at the community level. In yekolotemaries, females are not allowed to study Ethiopian Orthodox church to be become priests thus females were not participated in the study. Moreover, in prisoners there were few females as a result during the survey, no chance for females to be selected.
Furthermore, this study was limited to address the risk factors and the prevalence of LBRF.

\section{Conclusions}

The overall KAP levels of the high risk populations of this study showed that prisoners had highest level followed by street children. However, yekolotemaries had nil. As the sources of information received by the high risk populations' decreases, their KAP levels towards LBRF prevention also decreases proportionally. This showed that information on items assessing on knowledge and attitude towards LBRF prevention using television, radio and from their friends is essential to bring knowledge and attitudinal change.

In this study, knowledge and attitude were found to be associated with practice behaviors. This indicates that knowledge and attitudes of respondents was an important factor in practice behaviors towards LBRF prevention. Therefore, we recommended that despite the presence of other factors that hinder the knowledge and attitudes of high risk populations' in order to do practice; face to face health education should also be given as part of prevention strategy. Moreover, based on the above result (from tables 2), we recommended that in order to increase their knowledge and attitude, information on items assessing on knowledge and attitude towards LBRF prevention using television, radio and from their friends is essential to bring knowledge and attitudinal change towards LBRF prevention .

\section{Acknowledgments}

We would like to express great thanks to our colleagues: Mrs. Dagmawi Mengesha and Abebe Atinkut for data collection and assisting for data encoding. We are also indebted to Bahir Dar University for financing this research. Finally we would like to thank for all study participants who were involved in this study.

\section{Appendix -I}

i/ Items assessing knowledge of respondents towards louse- borne relapsing fever prevention

1. Which is a principal vector(s) for louse- borne relapsing fever $\mathrm{A} /$ body lice $\mathrm{B} /$ head lice $\mathrm{C} /$ pubic lice D/ all E/ I don't know

2. Is louse- borne relapsing fever a transmitting disease? A/ yes B/ no

3. How is louse- borne relapsing fever transmitted to humans A/ via bite of infected lice B/ via bite of Anopheles mosquitoes $\mathrm{C} /$ via bite of ticks(soft ticks) D/ I don't know

4. Which method is used to control louse- borne relapsing fever? A/ crashing of lice as soon as I found B/ combing my hair twice a day $\mathrm{C} /$ washing of body and clothes $\mathrm{D} / \mathrm{A} \& \mathrm{C}$

5. Is there treatment for louse- borne relapsing fever? $\mathrm{A} /$ yes $\mathrm{B} / \mathrm{no} \mathrm{C} / \mathrm{I}$ do not know 
6. Can you afraid of getting louse- borne relapsing fever if one of your families is infected? A/ yes B/ no

7. Can personal hygiene prevent from louse- borne relapsing fever transmission? A/ yes $\mathrm{B} / \mathrm{no} \mathrm{C} / \mathrm{I}$ do not know.

8. Do louse- borne relapsing fever patients have chills, head ache, and fever like malaria and typhoid fever? A/ yes B/ no C/ I don't know

9. Are flea, bugs and ticks transmitting louse- borne relapsing fever? A/ yes $\mathrm{C} /$ no $\mathrm{D} / \mathrm{I}$ don't know

ii/ Knowledge grading using 9 questions. A correct answer will give 1 score and 0 score for wrong answer. The scores vary from 0-9 points and will classify into 3 levels as follows: Bloom's cut off point, $60 \%-80 \%$.

Scores

Descriptions

7-9 (80-100\%)

High levels

4-6 (60-80\%)

Moderate levels

0- 3 (Less than 59\%)

Low levels

i/ Items assessing attitude of respondents regarding louseborne relapsing fever prevention

\section{A/ Positive statement}

1. The only methods of preventing louse-borne relapsing fever is delousing A/ strongly agree B/ agree C/ neither agree nor disagree D/ disagree E/ strongly disagree

2. Everybody has risk of being infected with louse-borne relapsing fever $\mathrm{A} /$ strongly agree $\mathrm{B} /$ agree $\mathrm{C} /$ neither agree nor disagree $\mathrm{D} /$ disagree $\mathrm{E} /$ strongly disagree

3. It is possible to recover from louse-borne relapsing fever A/ strongly agree $\mathrm{B} /$ agree $\mathrm{C} /$ neither agree nor disagree $\mathrm{D} /$ disagree $\mathrm{E} /$ strongly disagree

4. You are one of the important people in preventing louse-borne relapsing fever A/ strongly agree B/ agree $\mathrm{C} /$ neither agree nor disagree D/ disagree E/ strongly disagree

5. Eliminating lice can prevent from louse-borne relapsing fever $\mathrm{A} /$ strongly agree $\mathrm{B} /$ agree $\mathrm{C} /$ neither agree nor disagree $\mathrm{D} /$ disagree $\mathrm{E} /$ strongly disagree

\section{B/ Negative statement}

6. Louse-borne relapsing fever is diseases that can't be prevented $\mathrm{A}$ / strongly agree $\mathrm{B}$ / agree $\mathrm{C}$ / neither agree nor disagree $\quad \mathrm{D} /$ disagree $\mathrm{E} /$ strongly disagree

7. Once a person is infected with louse-borne relapsing fever he/ she can't get infected again $\mathrm{A} /$ strongly agree $\mathrm{B} /$ agree $\mathrm{C} /$ neither agree nor disagree $\mathrm{D} /$ disagree $\mathrm{E} /$ strongly disagree

8. Prevention of louse-borne relapsing fever is only the responsibility of health professionals $\mathrm{A} /$ strongly agree $\mathrm{B} /$ agree $\mathrm{C} /$ neither agree nor disagree $\mathrm{D} /$ disagree $\mathrm{E} /$ strongly disagree

9. Strong and healthy person will not get louse-borne relapsing fever $\mathrm{A} /$ strongly agree $\mathrm{B} /$ agree $\mathrm{C} /$ neither agree nor disagree $\mathrm{D} /$ disagree $\mathrm{E} /$ strongly disagree
10. Lice can't be controlled A/ strongly agree $B /$ agree $\mathrm{C} /$ neither agree nor disagree $\mathrm{D} /$ disagree E/ strongly disagree

ii/ Attitude grading using 10 questions. Individuals who will respond to 10 statements are a Likert's scale which include both positive and negative. The rating scale will be measured as follows:

Positive statement

Choice

Strongly agree

Agree

Neither agrees nor 3

disagrees

Disagree

Negative statement

Strongly disagree $1 \quad$ strongly disagree 5

The scores vary from $0-50$ and all individual answers will be summed up for total scores. The scores will be classified into 3 levels

Positive attitude $40-50$ scores $(80 \%-100 \%)$

Neutral attitude $30-39$ scores $(60 \%-80 \%)$

Negative attitude 0-29 scores (Less than 59\%)

i/ Items assessing practices of respondents regarding louse- borne relapsing fever prevention

1. How often they use combs for their hair? A/ usually $\mathrm{B} /$ sometimes $\mathrm{C} /$ rarely $\mathrm{D} /$ never

2. Habit of washing their body $\mathrm{A} /$ usually $\mathrm{B} /$ sometimes $\mathrm{C} /$ rarely $\mathrm{D} /$ never

3. Habit of ironing of their clothes A/ usually B/ sometimes $\mathrm{C} /$ rarely $\mathrm{D} /$ never

4. Habit of cutting of their hairs A/ usually B/ sometimes $\mathrm{C} /$ rarely $\mathrm{D} /$ never

5. Habit of using detergent to wash their body and clothes A/ usually $\mathrm{B} /$ sometimes $\mathrm{C} /$ rarely $\mathrm{D} /$ never

6. Habit of washing their hand after crashing lice $\mathrm{A} /$ usually $\mathrm{B} /$ sometimes $\mathrm{C} /$ rarely $\mathrm{D} /$ never

7. Habit of opening windows $\mathrm{A} /$ usually $\mathrm{B} /$ sometimes $\mathrm{C} /$ rarely $\mathrm{D} /$ never

8. Habit using insecticide to prevent lice infestations $\mathrm{A} /$ usually $\mathrm{B} /$ sometimes $\mathrm{C} /$ rarely $\mathrm{D} /$ never

ii/ Practices of the individuals towards louse- borne relapsing fever prevention( 8 questions). This part asks how often they use each personal protective measure against louse- borne relapsing fever and the rating scale will be measured as follows:

$\begin{array}{ll}\text { Usually } & 4 \\ \text { Sometimes } & 3 \\ \text { Rarely } & 2 \\ \text { Never } & 1\end{array}$

The scores range from 0 to 32 and will be classified into 3 levels.

Good practice

26-32 scores $(80 \%-100 \%)$

Fair practice

$20-25$ scores $(60 \%-80 \%)$

Poor practice

0-19 scores (Less than 59\%) 


\section{References}

[1] Cutler SJ: Possibilities for relapsing fever re-emergence. Emerg Infect Dis 2006, 12(3): 369-374.

[2] Tewdros E, Getahun A, Fekadu B: Relapsing fever in Hossana, Ethiopia: a clinical and epidemiological study. Ethip J Helth Sci 2002, 12(2):103-108.

[3] Dworkin MS, Anderson DE, Schwan JRTG, Shoemaker PC, Banerjee SN, Kassen BO, Burgdorfer W: Tick- borne relapsing fever in the North western United States and South western Canada. Clin Infect Dis 1998, 26:122-131.

[4] Raoult D, Roux V: The body louse as a vector of re-emerging human diseases. Clin Infect Dis 1999, 29:888-911.

[5] Durden LA: Lice, the phthiraptera. In Biology of disease vectors. 2nd edition. Edited by Marquardt WC. China: Dana Dreibelbis; 2004: 67-75.

[6] Shayeghi M, Salim abadi PY, Dehkoordi AS, Eshaghi A, Bazrafkan S: Epidemiology of head lice infestation in primary school pupils, in Khajeh city, east Azerbaijan province, Iran. Iranian J Arthropod-Borne Dis 2010, 4(1): $42-46$.

[7] Cutler SJ, Abdissa A, Trape JF: New concepts for the old challenge of African relapsing fever borreliosis. Clin Microbiol Infect 2009, 15: 400-406.

[8] Culter SJ: Relapsing fever a forgotten disease revealed. J App Microbiol 2010, 108: 1115-1122.
[9] Nordstrand A, Bunikis I, Larsson C, Tsogbe K, Schwan TG, Nilsson M, Sven Bergström S: Tick borne relapsing fever diagnosis obscured by malaria, Togo. Emerg Infect Dis 2007, 13(1):117-123.

[10] Bailey M, Prociv P, Petersen HP: Head lice and body lice: shared traits invalidat assumptions about evolutionary and medical distinctions. Australian J Med Sci 2003, 24(2):1-8.

[11] Internal medicine for health officers. The Ethiopian public health training initiative, the Carter centre, lecture note series. Ethiopia; 2006.

[12] Worku L, Gebre-Selassie S: Louse-borne relapsing fever profile at Jimma hospital, Ethiopia: a retrospective study. Ethiop J Educ Sc 2005, 1(1):60-64.

[13] Cutler SJ, Margarita Bonilla E, Singh RJ: Population structure of East African relapsing fever Borrelia spp. Emerg Infect Dis 2010, 6(7): 1076-1080.

[14] Tesfayohannes T: Prevalence of body lice in elementary school students in three Ethiopian towns at different altitudes. Ethiop Med J 1989, 27: 201-207.

[15] Badiaga S, Brouqui P: Human louse-transmitted infectious diseases. Clin Microbiol Infect 2012, 18: 332-337.

[16] Federal Democratic Republic of Ethiopia Population Census Commission: Summary and statistical Report of the 2007 Population and Housing Census: Population size by age and sex. Addis Ababa; 2008. 